\title{
Present and future use of cereals as feeds for livestock
}

\section{By J. F. D. Greenhalgh, Rovett Research Institute, Bucksburn, Aberdeen $A B 29 S B$}

Wherever cereals are grown, some are used as feeds for livestock; the subject of this paper is therefore considered first in international terms. A world survey in limited space must necessarily be superficial, and it is therefore followed by a more detailed analysis of cereal usage by livestock in one country, the United Kingdom.

\section{World cereal production and utilization}

The United Nations Food and Agriculture Organization (FAO, 1975) analysed production and consumption of cereals in 1970 and estimated corresponding values for 1980,1985 and 1990 (Fig. I). In 1970, livestock ate more than $60 \%$ of the cereals consumed in the developed countries but less than $10 \%$ of those consumed in the rest of the world. By 1990 these proportions are estimated to increase to 67 and $15 \%$, respectively. In absolute terms, the consumption of

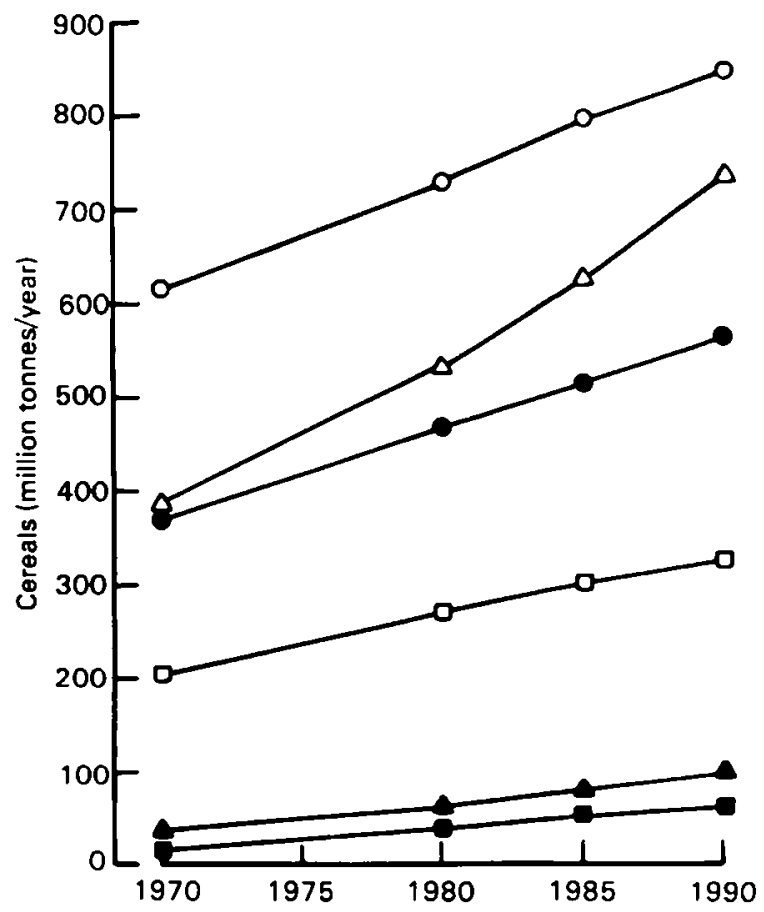

Fig. I. Present and future demand for cereals, expressed as total consumption (open symbols) or consumption as animal feed (closed symbols), for developed countries $(\mathrm{O}, \mathrm{O})$, developing countries $(\triangle, \Delta)$ and Asian centrally-planned economies $(\square, \square)$ (Food and Agriculture Organization, 1975). 
cereals by livestock is estimated to rise in 20 years by 194 million tonnes in the developed countries $(52 \%)$ and by 112 million tonnes $(221 \%)$ in the rest of the world.

\section{Utilization of cereals for animal feeding in the United Kingdom}

Data sources. The concentrated feeds consumed by farm livestock fall into three categories: (a) compounds; mixtures of cereals and other feeds prepared by feed compounders, (b) purchased straights; individual feeds bought by farmers from merchants, and (c) retained straights; feeds used on their farm of origin or sold direct from farm to farm. The Annual Abstract of Statistics gives data for (a) only; of the Ministry of Agriculture publications, Output and Utilization of Farm Produce in the United Kingdom includes both (a) and (b) and, like the Annual Review of Agriculture, adds estimates of (c). The last two sources include some breakdown of compounds into their components.

Cereal production in the United Kingdom may be compared with that of other countries in the Commonwealth Secretariat's Grain Crops (an annual which ceased publication in 1972) and Grain Bulletin (monthly). The Ministry of Agriculture publications also provide data for output of livestock products.

When used to analyse current cereal usage and estimate future demand, these statistics may require various adjustments. For example, total quantities of cereals consumed by animals have to be allocated among the classes of livestock. This and other problems are referred to by Sturgess \& Reeves (1972) and Sturgess (1974).

Table 1. Output of animal products and inputs of concentrates and their cereal components (UK, 1971-72)*

Product $\begin{gathered}\text { Product } \begin{array}{c}\text { output } \\ \text { (million tonnes)(million tonnes) }\end{array} \\ \begin{array}{c}\text { Concentrate } \\ \text { Concentrates Cereals }\end{array}\end{gathered}$

Milk

Beef (dressed carcass)

Pig meat (dressed pork equivalent)

Poultry meat (dressed)

Eggs $(57 \mathrm{~g})$

Sheep meat (dressed carcass)

$13 \cdot 46$

0.59

$\mathbf{1} \cdot \mathbf{1}$

0.56

0.85

0.23
$4 \cdot 92$

$2 \cdot 34$

$5 \cdot 30$

$1 \cdot 92$

$3 \cdot 76$

0.51
0.37

4.05

$5 \cdot 35$

$3 \cdot 50$

$4 \cdot 5 I$

$\mathbf{2} \cdot \mathbf{2 2}$
0.25

$2 \cdot 27$

$4 \cdot 01$

$2 \cdot 73$

$3 \cdot 65$

$1 \cdot 66$

-Main source: Sturgess (1974).

Current use of cereals by livestock. Estimates of total concentrate and cereal inputs, and of animal product output, are given in Table I for the UK in $1971-72$. The value for 'net' beef excludes that imported 'live' as store cattle from Ireland. Meat from culled breeding stock (dairy cows and laying hens) is also excluded on the grounds that it is a byproduct of milk or egg production (Sturgess \& Reeves, 1972). The contribution of cereals to total concentrates varies considerably between classes of animal, and reflects the greater ability of the ruminants to utilize fibrous byproducts such as milling offals, other cereal residues and sugar beet pulp. 
The input:output ratios provide considerable food for thought. The apparent input of concentrate per unit of milk is almost as great as the common feeding standard $(0.4 \mathrm{~kg} / \mathrm{kg}$ milk), but includes concentrates given to young dairy animals and dry cows; it is therefore slightly greater than values commonly quoted for lactating cows alone, of about $0.35 \mathrm{~kg} / \mathrm{kg}$ milk (e.g., Milk Marketing Board, 1976). Nevertheless, to a nutritionist interested in pasture utilization, even $0.35 \mathrm{~kg}$ concentrates $/ \mathrm{kg}$ milk is a somewhat depressing statistic.

The ratios for the meat-producing animals do not support the widely held belief that ruminants produce meat from forages and thus require much smaller inputs of concentrates than do pigs and poultry. In fact, poultry require less concentrate per unit of carcass meat than do beef cattle although, as discussed later, it is erroneous to regard beef and poultry meat as being isometrically equivalent. Wilkinson (1976) has estimated the concentrate consumption of UK beef cattle to be 3.9 million tonnes/annum, or considerably more than the value of Table $I$.

According to Ashton (1975), concentrates supply about $40 \%$ of the total energy requirements of livestock in the UK, the remainder being met by forages.

Recent trends and predictions. To take the values of Table $\mathrm{I}$ and project them into the future requires a consideration of many factors: demographic, economic and technical. Future UK demand for animal products will depend on the number of people in the country and their buying power. The proportion of that demand which is met from UK animal production will depend on the nation's trading position. The total animal feed resources needed to produce the meat, milk and eggs required will depend in the first instance on the technical efficiency of animal production, and economic circumstances are thought likely to determine the subdivision of feed, first between concentrates and coarse fodders and then among the various concentrate constituents.

To predict future trends one usually starts with the past. Fig. 2 shows past trends in total concentrate and total cereal usage for feeding animals in the UK. From 1960 to 1972 there were steady upward trends in both sets of values, which changed only after a dramatic increase in cereal prices in 1973. Throughout the period described by Fig. 2, the proportion of cereals in concentrates remained about the same.

Sturgess \& Reeves (1972) used econometric models of UK agriculture to prepare comprehensive estimates of cereal requirements for animal feeding for $1977-78$, the year when the UK was anticipated to be fully incorporated into the EEC. The economic upheavals which began in 1973 and have continued, at least in Britain, until the present day, prompted Sturgess (1974) to revise some of his earlier predictions. Requirements for concentrates and cereals as predicted by Sturgess \& Reeves (1972) and Sturgess (1974) are included in Fig. 2. Both predictions for concentrates in fact depart very little from earlier trends, and despite the pronounced fall in concentrate usage from 1973 to 1975 they now seem likely to be on target. However, the same cannot be said for cereal requirements, which appear likely to have been considerably underestimated by Sturgess \& Reeves (1972) and, to a smaller extent, by Sturgess (1974). They anticipated that EEC cereal prices 


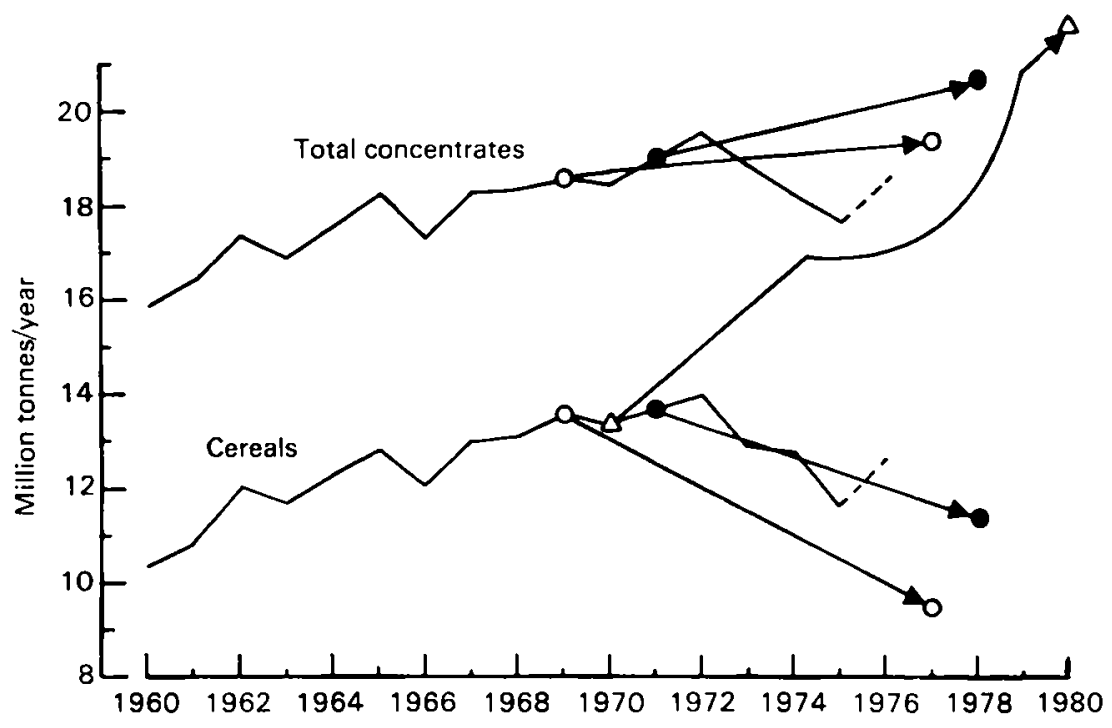

Fig. 2. Consumption of total concentrates and cereals by UK livestock, including estimates for 1976. Projections shown thus: $O \rightarrow O$, Sturgess \& Reeves (1972); $\rightarrow \rightarrow$, Sturgess (1974); $\Delta \rightarrow \Delta$, FAO (1971).

would be considerably greater than world prices and that the UK, in common with her EEC partners, would import considerable quantities of cereal substitutes such as cassava. Sturgess \& Reeves (1972) predicted the cereal content of concentrates to fall from $73 \%$ in $1969-70$ to $49 \%$ in $1977-78$. There is little evidence so far for such a dramatic change, probably because the gap between world and EEC cereal prices has been smaller than expected. Sturgess (1974) estimated that between 1971-72 and $1978-79$ the cereal content of purchased compounds would fall from 6 I to $57 \%$, although other forecasters had, slightly earlier, predicted falls to as low as $5-35 \%$ by the time the UK became a full member of the EEC (Campbell, 1972; Crabtree, 1972; Horst, 1972; Phillips, 1973).

Also included in Fig. 2 is an extremely optimistic projection from 1970 to 1980 for use of cereals in livestock feeds (Food and Agriculture Organization, 1971).

\section{Nutritional factors affecting demand for cereals}

Nutritionists will be impressed by the detailed, painstaking approach of economists to the prediction of future demand for cereals, but they should always bear in mind that the fundamental determinants of demand for cereals are nutritional. They are, first, what quantities of animal products man the consumer chooses to eat, and second, how man the farmer chooses to produce these quantities. The economist may argue that both choices are to a large extent determined by economic factors, and in particular, by the prices of animal products and cereals, relative to one another and relative to prices of alternative foods or feeds. 
Consumer demand for animal products. The notion that the quantities of meat, milk and eggs we consume 10 or 20 years hence will be decided largely by price relativities is too deterministic. We have considerable freedom of choice in selecting our diet, our use of cereals to provide livestock products being evidence of this. As we become richer we tend to spend a declining proportion of our income on food, despite the increasing complexity of our purchases with regard to country of origin and degree of preparation. Over the past decade consumption per head of food nutrients in the UK has changed remarkably little; carbohydrate (and energy) intake has declined slightly, but animal protein consumption has varied from year to year only between $51 \cdot 1$ and $52.8 \mathrm{~g} / \mathrm{d}$. Instead of asking the question 'How much will beef (or milk or eggs) cost in 1997 and how much shall we be able to afford?' we should ask 'How much of each food shall we choose to consume in 1997 and how best can we produce it?' The answers may be influenced by health considerations and by concern for the needs of hungrier nations, as well as by personal tastes; the important point is that even today, prices may have less effect on our choice of foods than economists would have us believe.

If we choose to maintain our animal protein intake at about the present level, we may still vary our consumption of individual products. Before 1970 there was a strong trend for poultry meat to compete with meat from ruminants. One might suppose that a switch from ruminant flesh to poultry would increase the demand for concentrates and hence for cereals. Table I confirms this view for sheep meat although not for beef, but in fact the comparison is complicated by two further considerations. In terms of consumer satisfaction, $\mathrm{I}$ kg beef carcass is equivalent to approximately $\mathrm{I} \cdot 5 \mathrm{~kg}$ poultry carcass (Fisher \& Bender, 1975). Furthermore, the cereal content of poultry feeds is higher than that of the concentrates given to beef cattle; in $1969-70$ the relative proportions were 78 and $56 \%$ (Sturgess \& Reeves, 1972). It therefore seems that a $10 \%$ switch by the consumer from beef to poultry meat would increase cereal demand by about $8 \%$.

Cereal input per unit of animal product. This ratio can be changed by two mechanisms: either the efficiency of the animal is changed or, more simply, diet proportions are altered; in practice the two mechanisms rarely operate independently.

Each input:output ratio in Table $\mathrm{I}$, and also in Fig. 3, is calculated from the concentrate input for the whole sector of the animal industry used to produce the output. In addition to the concentrates given to animals actually producing meat, milk or eggs, inputs include concentrates consumed by breeding stock and, in the case of dairy cattle and laying hens, those consumed during the rearing period. For example, in a sample of commercial pig herds the sow consumed on average $86 \mathrm{~kg}$ concentrates for each bacon pig produced, or about $24 \%$ of total concentrate input (Ridgeon, 1976). By increasing litter size and by increasing the frequency of breeding it might be possible to spread the overhead feed input of breeding stock over twice as many offspring per year as at present (Braude, 1972), which would reduce total concentrate input per bacon pig by about $12 \%$. For poultry the feed inputs of breeding stock are a very small proportion of total feed inputs. For 


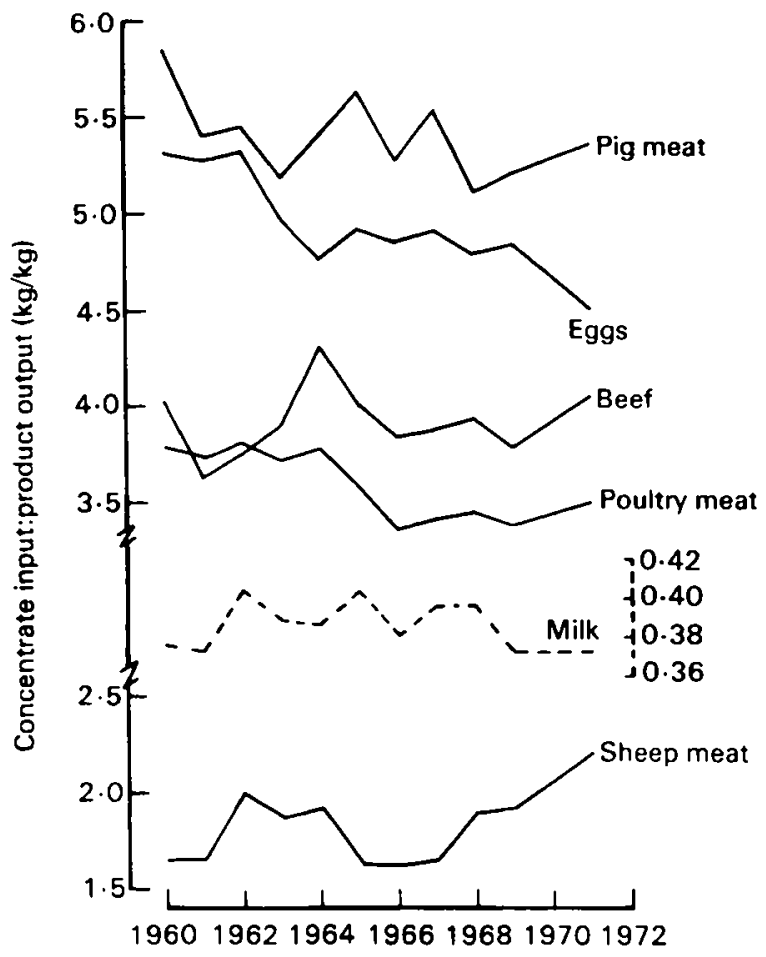

Fig. 3. Secular changes in input of concentrate feed per unit of animal product from UK agriculture (Sources: Sturgess \& Reeves, 1972; Sturgess, 1974).

ruminants there is considerable scope for reducing the overhead feed input to breeding stock, but the proportion of concentrate in the feed of beef cows and breeding ewes is relatively small. There is scope for a reduction in the rearing period of dairy heifers, but as this is likely to be achieved by increasing the proportion of concentrates in the diet, the effect on the intput:output ratio for milk will be small.

The maintenance requirement of the actual producer of meat, milk or eggs represents a further overhead element in its feed input, and the aim in intensive systems of livestock production is to reduce the importance of this by increasing production per unit time. The crucial factor in intensification is the energy intake of the animal. With all classes of animal, energy intake may be determined by the energy concentration of the diet, hence the importance of concentrate feeds. During the process of intensification, concentrates replace other feeds and the concentrate:product ratio increases, until the diet consists entirely of concentrates. In the UK, ruminants are in the earlier stages of intensification, and their contribution to future demand for concentrates will be extremely sensitive to the degree of intensification adopted. Pigs and poultry, on the other hand, are so dependent on concentrates that only a considerable 'de-intensification' (which seems unlikely) would reduce the demand for concentrates. For non-ruminants the 
main factors determining the input:output ratio are likely to be further genetic improvements, in appetite and in the conversion of concentrates into carcass meat.

For all species, modification of body composition will have an important influence on input:output ratios. Body fat contains seven to eight times as much energy per unit weight as lean tissue, and despite the lower energetic efficiency of protein synthesis (Ørskov \& McDonald, 1970; Kielanowski, 1976), it seems that the replacement of fat by lean tissue reduces the net requirement for dietary energy (and hence for cereals) per unit weight of meat by a factor of about three. What is difficult to predict is the acceptance of leaner meat by the consumer.

Alternatives to cereals. In addition to being concentrated sources of energy, cereals have advantages over most other feeds with respect to storage, transport and predictability of composition, and are often difficult to replace. The main alternatives are listed in Table 2. Direct replacements for cereals in concentrates include cereal byproducts, sugar beet pulp and molasses, and also cassava (the dried starchy root of the tropical plant Manihot esculenta). All share with cereals the advantages listed above. The first three, however, are available in the UK in strictly limited quantities which are unlikely to change unless we increase considerably our consumption of flour and other refined cereals, alcoholic drinks or sugar. They already make appreciable contributions to UK concentrates, the cereal offals comprising about $10 \%$ of these feeds and the sugar byproducts, $5 \%$. Cassava could be imported in large quantities under advantageous EEC tariff arrangements, but to do so would conflict with our national aim of greater selfsufficiency (Ministry of Agriculture, Fisheries and Food, 1975) and also deprive tropical countries of food or feed.

\section{Table 2. Substitutes for cereals as feeds for livestock}

$\begin{array}{lc}\text { Feed } & \begin{array}{c}\text { Approximate UK } \\ \text { production (million } \\ \text { tonnes dry matter) }\end{array} \\ \text { Cereals } & 12 \\ \text { Cereal byproducts } & 1 \cdot 5 \\ \text { Sugar byproducts } & 0.6 \\ \text { Root crops } & 0.7 \\ \text { Pasture herbage, grazed } & 22 \\ \text { Pasture herbage, conserved } & 11 \\ \text { Other fodder crops } & 0.6 \\ \text { Cereal straws } & 8\end{array}$

The root crops grown in the UK for livestock feeding are swedes (Brassica napus), turnips (B. campestris), fodder beet and mangolds (both Beta vulgaris). In contrast to cassava they contain a low concentration of dry matter (DM) (0. I-0.2) and sugars instead of starch. Nevertheless, they may be regarded as substitutes for cereals. Recent experiments with ruminants (Kay, 1975) have established that approximately I I $\mathrm{kg}$ root DM can successfully replace I $\mathrm{kg}$ concentrate DM, but for pigs, root crops are generally less well utilized than concentrates (Livingstone, Jones \& Mennie, 1977). The DM yield of root crops in the UK is equivalent to $6 \%$ 
of cereal grain production, but the root crops are grown on an area only $3 \%$ of that devoted to cereals. A switch from cereals to root crops is therefore attractive as a means of increasing output of animal products per unit area of land, but would reduce the demand for cereals only if undertaken on a considerable scale. Root crops yield DM at lower unit cost than cereals, but this attractiveness to the farmer is diminished by greater difficulties of cultivation, harvesting and storage.

For ruminants, as Table 2 shows, the important alternatives to cereals are grass (fresh or conserved) and other green fodder crops. Table 2 also shows that small proportional increases in the output of these feeds could, at least in theory, lead to the replacement of a relatively large proportion of cereals. In fact, the DM harvested from UK pastures could be increased very considerably, merely by the more widespread application of the improved management techniques currently used on better farms. The National Economic Development Office (1974) considered a $40 \%$ improvement in 10 years to be technically feasible; on paper, this would be sufficient to replace all the concentrates currently given to ruminants.

On the farm, replacement of concentrates by forages is not so easily accomplished. The technical difficulties of replacement cannot be fully discussed here, but the problem is one of energy concentration. The only forages capable on their own of giving animal production rates comparable to those achieved with the aid of concentrates are grazed immature pasture herbage, a somewhat ephemeral feed, or the same herbage dried, ground and pelleted, a durable but expensive product. Many forages, grazed or conserved, are suitable only as maintenance feeds and are thus not genuine alternatives to cereals. Their contribution to animal production is well illustrated by results from the Milk Marketing Board's (r976) low-cost production farms. These are dairy farms with better than average grassland utilization, employing heavy dressings of fertilizer nitrogen (two to three times the national average for grassland) and high stocking rates (approximately $40 \%$ higher than the national average), yet their concentrate usage $(0.36 \mathrm{~kg} / \mathrm{kg}$ milk) is sufficiently high to account for $90 \%$ of the milk produced.

Thus although grass and forage crops are potentially capable of replacing a considerable proportion of the cereals of ruminant diets, they are unlikely to do so unless (a) there is a general improvement in their net energy value or (b) concentrates become so expensive that less intensive systems of ruminant production become more profitable.

\section{Conclusions}

There are no obvious technical obstacles to continuing the present contribution of cereals to livestock feeding in the UK. On the one hand, general trends for intensification of animal production are likely to stimulate demand for cereals. On the other hand, improvements in efficiency of feed utilization and, perhaps, in the nutritive value of alternative feeds, should reduce demand. One of the more important economic factors is that the EEC is approaching self-sufficiency in cereal grains and will need to pitch prices at levels ensuring that about $65 \%$ of production is used for animal feed (or perhaps exported). On a world scale the 
morality of feeding livestock on cereals has been questioned (e.g. Greenhalgh, 1976), although it should be pointed out that the developed countries, which are those using the greater part of their cereals for animal feed, are collectively selfsufficient; they are not directly depriving less fortunate peoples of cereals.

The future of cereals as livestock feed therefore seems bright. The only clouds on the horizon are depicted by the two lowest lines in Fig. 1. By 1985 a significant proportion of the demand for cereals in the developing countries and centrallyplanned economies will be for animal feeds. Yet in that year, $75^{\circ}$ million people in those countries are likely to be malnourished (Food and Agriculture Organization, 1975). The developed countries may well be able to maintain, and even increase, their somewhat profligate usage of cereals for animal feed; the important questions are whether the rest of the world will wish to follow their example and, if so, how they will find the means to do so.

\section{REFERENCES}

Ashton, J. (1975). Rep. Grassld Res. Inst. p. II3.

Braude, R. (1972). In The Improvement of Sow Productivity [A. S. Jones, V. R. Fowler and J. C. R. Yeats, editors]. Occ. Publ. Rowett Res. Inst. no. 3.

Campbell, A. J. (1972). Institute of Corn and Agricultural Merchants, Technical Newscast, March 1972.

Crabtree, J. R. (1972). The Composition of Compound Feedstuffs under UK and EEC Conditions. Hurley: Grassland Research Institute.

Fisher, P. \& Bender, A. E. (1975). The Value of Food (2nd edn). London: Oxford University Press.

Food and Agriculture Organization (1971). Agricultural Commodity Projections, 1970-1980. Rome: FAO.

Food and Agriculture Organization (1975). The State of Food and Agriculture, 1974. Rome: FAO.

Greenhalgh, J. F. D. (1976). Anim. Feed Sci. Technol. 1, 1.

Horst, J. R. (1972). Compound Feeds in the United Kingdom: Effects of Support Policies on Use of Ingredients Rep. USDA-ERS, no. 324 .

Kay, M. (1975). In Simplified Feeding for Milk and Beef. London: U.S. Feed Grains Council.

Kielanowski, J. (1976). In Protein Metabolism and Nutrition [D. J. A. Cole et al., editors] London: Butterworths.

Livingstone, R. M., Jones, A. S. \& Mennie, I. (1977). Anim. Feed Sci. Technol. 2, 31.

Milk Marketing Board (1976). An Analysis of LCP Costed Farms, 1975-76 Report of the LCP Information Unit, no. 7 .

Ministry of Agriculture, Fisheries \& Food (1975). Food from our own Resources. Cmnd. 6020 London: HM Stationery Office.

National Economic Development Office (1974). UK Farming and the Common Market: Grass and Grass Products London: NEDO.

Ørskov, E. R. \& McDonald, I. (1970). In Energy Metabolism of Farm Animals [A. Schurch \& C. Wenk, editors]. Zurich: Juris Druck.

Phillips, T. P. (1973). Cassava: $A$ Study of Utilization and Potential Markets. Canada: University of Guelph.

Ridgeon, R. F. (1976). Pig Management Scheme Results for 1975. Agricultural Economics Unit, University of Cambridge, Economic Report no. 37.

Sturgess, I. M. (1974). The Impact of the CAP for Cereals on Feed Compounding in the UK. Agricultural Adjustment Unit, University of Newcastle upon Tyne.

Sturgess, I. M. \& Reeves, R. (1972). The Potential Market for British Cereals. Agricultural Adjustment Unit, University of Newcastle upon Tyne.

Wilkinson, J. M. (1976). In Improving the Nutritional Efficiency of Beef Production [J. C. Tayler and J. M. Wilkinson, editors]. Luxembourg: Commission of the European Communities.

\section{Printed in Great Britain}

